\title{
InAs Colloidal Quantum Dots Synthesis via Aminopnictogen Precursor Chemistry
}

\author{
Valeriia Grigel, Dorian Dupont, Kim De Nolf, Zeger Hens* and Mickael D. Tessier* \\ Physics and Chemistry of Nanostructures, Ghent, Belgium. \\ Center for Nano and Biophotonics, Ghent University, Ghent, Belgium.
}

\section{Supporting Information}

S1: InAs QDs synthesis protocol.

S2: Byproduct and InAs QDs separation and elemental analysis.

S3: Reaction chemical yield evaluation.

S4: QDs purification method for TEM analysis.

S5: Histogram of size distribution of InAs QDs after purification.

S6: XRD and EDX analysis of InAs QDs.

S7: Gas analysis of the reaction between $\mathrm{As}\left(\mathrm{NMe}_{2}\right)_{3}$ and oleylamine.

S8: aminoarsine:aminophosphine ratio study

S9: InAs/ZnS and InAs/ZnSe QDs protocols.

S10: TEM pictures of InAs/ZnS and InAs/ZnSe QDs.

S11: XRD diffractograms of InAs/ZnS and InAs/ZnSe QDs. 


\section{S1 InAs QDs synthesis protocol}

\section{S1.1 Chemicals}

Indium(III) chloride (99.999\%), zinc(II) chloride ( $\geq 98 \%$ ), tris(diethylamino)phosphine (97\%), selenium powder 100 mesh (99.99\%) and zinc stearate (technical grade, $65 \%$ ) were purchased from Sigma Aldrich. Tris(dimethylamino)arsine (99\%), trioctylphosphine (> $97 \%$ ) and sulfur powder were purchased from Strem Chemicals. Oleylamine (80-90\%) was purchased from Acros Organics. Octadecene (technical $90 \%$ ) was purchased from Alfa Aesar.

\section{S1.2 InAs QDs with exciton at $800 \mathrm{~nm}$ (estimated diameter: $3.4 \mathrm{~nm}$ )}

$200 \mathrm{mg}(0.9 \mathrm{mmol})$ of indium(III) chloride and $600 \mathrm{mg}(4.4 \mathrm{mmol})$ of zinc(II) chloride are mixed in $5.0 \mathrm{~mL}(15 \mathrm{mmol})$ of technical oleylamine. The reaction mixture is stirred and degassed at $120{ }^{\circ} \mathrm{C}$ for an hour and then heated to $190{ }^{\circ} \mathrm{C}$ under nitrogen. When the temperature achieves $190{ }^{\circ} \mathrm{C}$, a volume of $0.17 \mathrm{~mL}(0.9 \mathrm{mmol})$ of tris(dimethylamino)arsine (In:As=1:1) is quickly injected in the mixture. 30 minutes after this latter injection, a volume of $0.74 \mathrm{~mL}(2.7 \mathrm{mmol})$ of tris(diethylamino)phosphine (In:As:P=1:1:3) is quickly injected in the mixture. After the phosphorus precursor injection, the InAs nanocrystals synthesis proceed. The InAs core QDs reaction occurs during 30 minutes. At the end of the reaction, the temperature is cooled down. InAs nanocrystals are then precipitated in ethanol and suspended in toluene. This synthesis provides InAs nanocrystals with a diameter of $3.4 \mathrm{~nm}$ (excitonic absorption peak at $800 \mathrm{~nm}$ ).

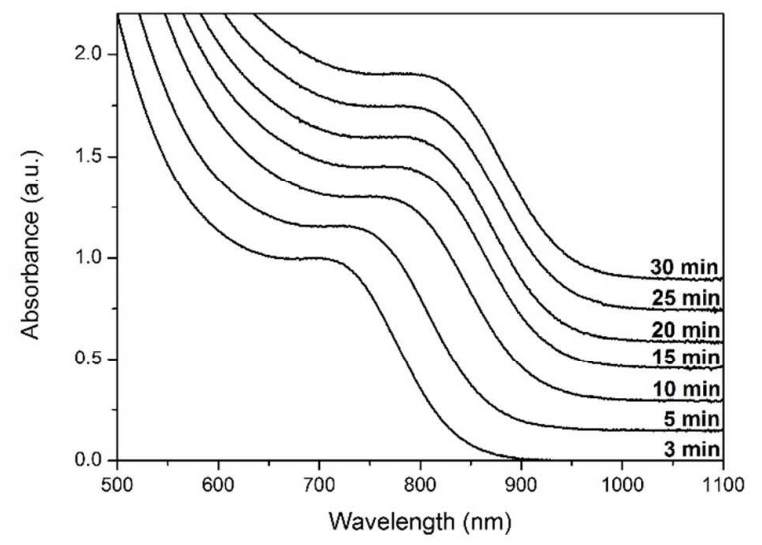

Figure S1. Evolution of the absorption spectrum of InAs QDs in time during reaction. 


\section{S2 Byproduct and InAs QDs separation and elemental analysis.}

For this analysis, InAs QDs were washed 3 times using ethanol and toluene as the nonsolvent and the solvent, respectively. The reaction byproduct was pelleted through centrifugation and separated from the InAs QDs by decantation. Figure S2 shows absorption spectra of the InAs QD dispersion before and after removal of this byproduct. X-Ray Fluorescence analysis (XRF) reveals that the thus obtained InAs QDs have a consistent indium to arsenic ratio ((In:As = 1.1:1, see Figure S3), wheres the byproduct pellet is mostly composed of arsenic (In:As = 0.12:1, see Figure S4).

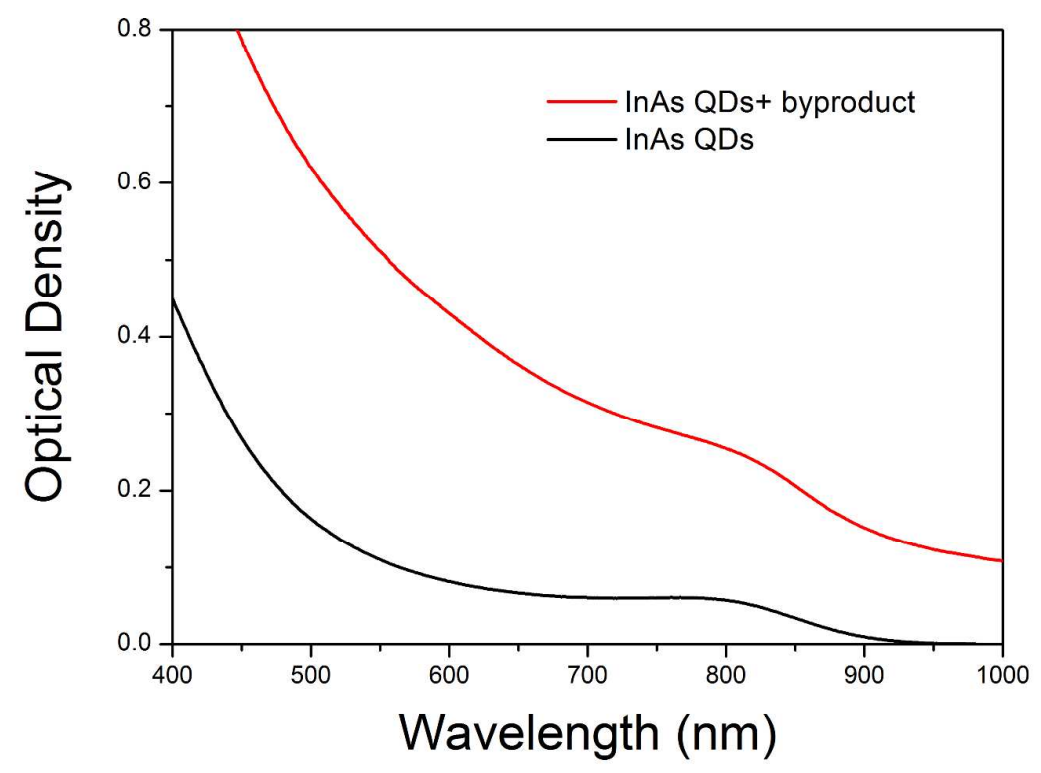

Figure S2. Absorbance spectra of aliquot after synthesis (red line) and InAs QDs separated from the turbid byproduct (black line). 
a.

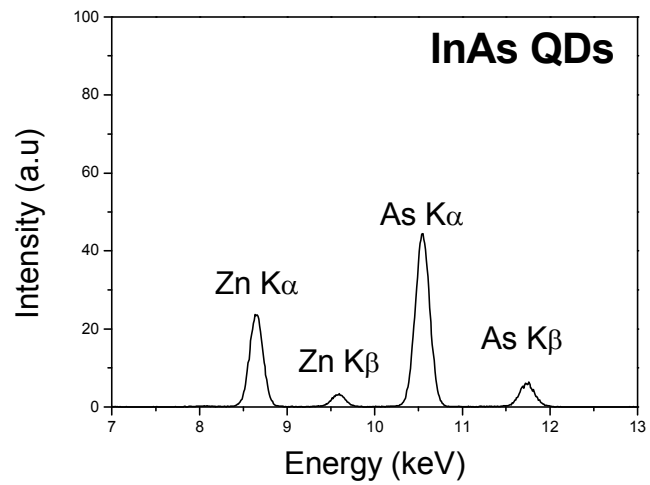

b.

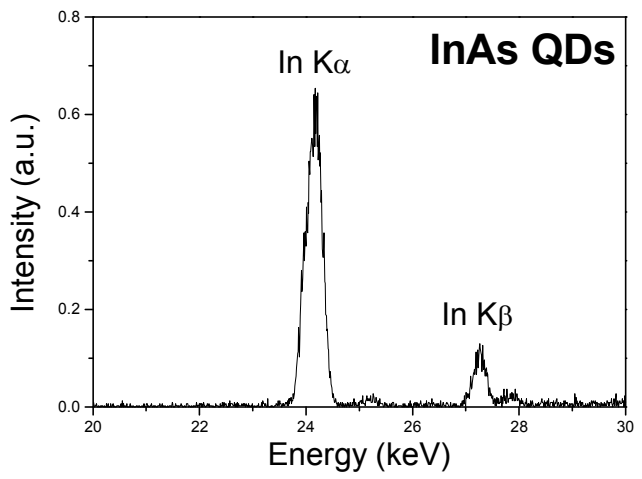

Figure S3: XRF spectra of InAs QDs sample using different secondary target: a. Molybdenum target and $\mathbf{b}$. Aluminum target.

a.

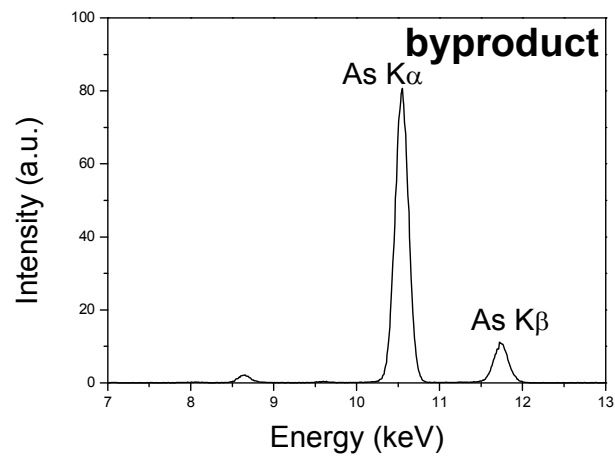

b.

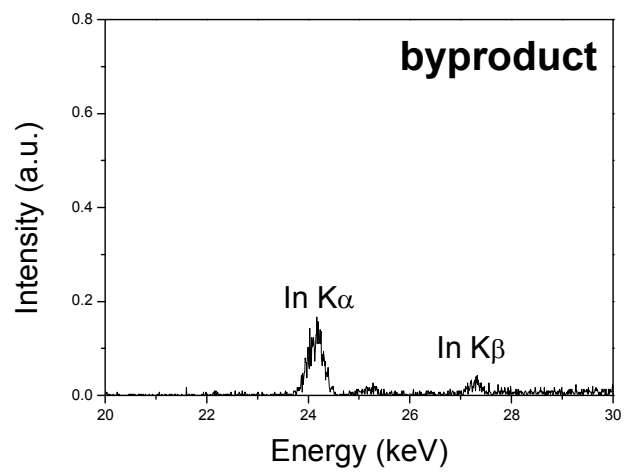

Figure S4: XRF spectra of byproduct using different secondary target: a. Molybdenum target and $\mathbf{b}$. Aluminum target. 


\section{S3 Chemical yield evaluation method}

The chemical yield is estimated by measuring the absorbance of a known dilution of the reaction mixture at short wavelengths $(413 \mathrm{~nm})$. The dilution is estimated by first measuring the mass of the aliquot withdrawn from the mixture. Then a known volume of toluene is added to the aliquot. The absorbance of the provided solution is then measured. It is wellknown that the intrinsic absorption coefficient of colloidal nanocrystals are close to those of bulk materials in the short wavelength range. ${ }^{1}$ Knowing the intrinsic absorption coefficient of bulk InAs, we can then use these values to calculate the chemical yield of InAs QDs in the synthesis proposed here.

\section{Example:}

An aliquot with a measured volume $\mathrm{V}_{\text {aliquats }}=15 \mu \mathrm{L}$ is withdrawn from the reaction mixture after removal of the byproduct (see supporting information S2). In this example, the total volume of the reaction mixture $\mathrm{V}_{\text {Total }}$ is $6 \mathrm{~mL}$. Then, $3.0 \mathrm{~mL}$ of toluene is added to the aliquot and the whole solution is loaded in an absorbance cuvette. An absorbance A of 0.58 is measured at $\lambda=413 \mathrm{~nm}$ for the aliquot in toluene. According to literature, ${ }^{2}$ the intrinsic absorption coefficient is given by:

$$
\mu_{i, t h}=\frac{4 \pi n k\left|f_{L F}\right|^{2}}{n_{S} \lambda}
$$

Here, $n$ and $k$ are the real and imaginary part of the refractive index of bulk zinc-blende InAs and $n_{\mathrm{S}}$ is the refractive index of toluene. The local field factor $f_{L F}$ is given by: ${ }^{2}$

$$
\left|f_{L F}\right|^{2}=\frac{9 n s 4}{\left(\mathrm{n}^{2}-\mathrm{k}^{2}+2 \mathrm{n}_{\mathrm{s}}^{2}\right)^{2}+4(\mathrm{nk})^{2}}
$$

We can have access to $n, k$ and $n^{s}$ from the literature, ${ }^{3,4}$ which yields at $\lambda=413 \mathrm{~nm}: n=$ 3.197, $k=2.034, n_{s}=1.52$. Then $\left|f_{L F}\right|^{2}=0.170$ and $\mu_{i, t h}=2.2 \cdot 10^{7} \mathrm{~m}^{-1}$.

We can then deduce the volume fraction $f$ of InAs in the aliquot with the measured absorbance $A$ and the theoretical intrinsic absorption coefficient $\mu_{i, t h}:^{2}$

$$
f=\frac{A \cdot \ln (10)}{\mu_{i, t h} \cdot L}=6.0 \cdot 10^{-6}
$$

Where $L$ is the cuvette length $(m)$. The amounts of InAs units can then be deduced from $f$ and the InAs molar volume $V_{M}$.

$$
n_{\text {cuvette }}=f \cdot \frac{\mathrm{v}_{\text {cuvette }}\left(\mathrm{m}^{3}\right)}{\mathrm{V}_{\mathrm{M}}\left(\frac{\mathrm{m}^{3}}{\mathrm{~mol}}\right)}=6.0 \cdot 10^{-6} \cdot \frac{3.0 \cdot 10^{-6}}{3.4 \cdot 10^{-5}}=5.4 \cdot 10^{-7} \mathrm{~mol}
$$

The total amount of InAs units in the reaction mixture can be calculated with the ratio between the volume of the aliquot $\mathrm{V}_{\text {aliquats }}$ and the volume $\mathrm{V}_{\text {Total }}$ of the reaction mixture.

$$
n_{\text {Total }}=n_{\text {cuvette }} \cdot \frac{\mathrm{V}_{\text {Total }}}{\mathrm{V}_{\text {aliquats }}}=5.4 \cdot 10^{-7} \cdot \frac{6 \cdot 10^{-3}}{15 \cdot 10^{-6}}=0.22 \mathrm{mmol}
$$


We have defined the chemical yield C.Y. as a percentage between the amount of InAs units in the reaction mixture $n_{\text {Total }}$ and the amount of $\ln n_{I n}$ that we have initially added to the reaction mixture.

$$
C . Y .=\frac{\text { nTotal }}{n_{\text {In }}} \cdot 100 \%=\frac{0.22}{0.45} \cdot 100 \%=49 \%
$$

For this particular example we have estimated a chemical yield of $49 \%$. It means that $49 \%$ of the initially used indium precursor has been effectively converted into InAs nanocrystals at the moment of the reaction we have taken this aliquot. 


\section{S4 QDs purification method for TEM analysis.}

The following purification method is used to increase the quality of TEM images of InAs QDs.

InAs QDs and the byproduct are first separated by decantation (cf. supporting information S2). $0.6 \mathrm{~mL}$ of octylamine and $1.2 \mathrm{~mL}$ of ethanol is added to $0.2 \mathrm{~mL}$ of InAs QDs ( $5 \%$ of the total amount of one reaction). The mixture is precipitated using 5 min of centrifugation at $3700 \mathrm{rpm}$. The precipitate is suspended in $0.2 \mathrm{~mL}$ of toluene and $1 \mathrm{~mL}$ of octylamine and 0.8 $\mathrm{mL}$ of ethanol are added to the obtained solution once more. The resulting turbid mixture is then centrifuged for $5 \mathrm{~min}$ at $3700 \mathrm{rpm}$ and the obtained precipitate is suspended in $0.2 \mathrm{~mL}$ of toluene. The obtained solution is used to deposit the purified InAs QDs on a TEM grid by dip-coating. It should be noted that the excitonic feature of the purified InAs QDs is at the same position before and after purification (cf. figure S5 below) showing that this method is not size-selective.

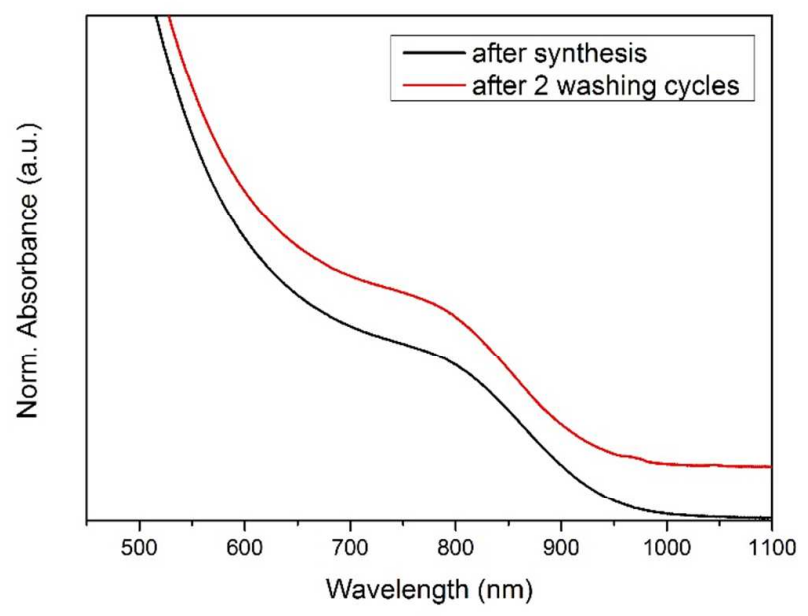

Figure S5: Absorption spectra of InAs QDs solution before and after purification method. Spectra have been shifted vertically for clarity. 


\section{S5 Histogram of size distribution of InAs QDs after purification.}

The purification method for TEM analysis is performed on InAs QDs that present an excitonic feature at $800 \mathrm{~nm}$ (cf. absorption spectra in supporting information S4). The purified InAs QDs are deposited on a TEM grid by dip-coating. The diameter of each QDs is estimated by measuring the QDs area using ImageJ software.

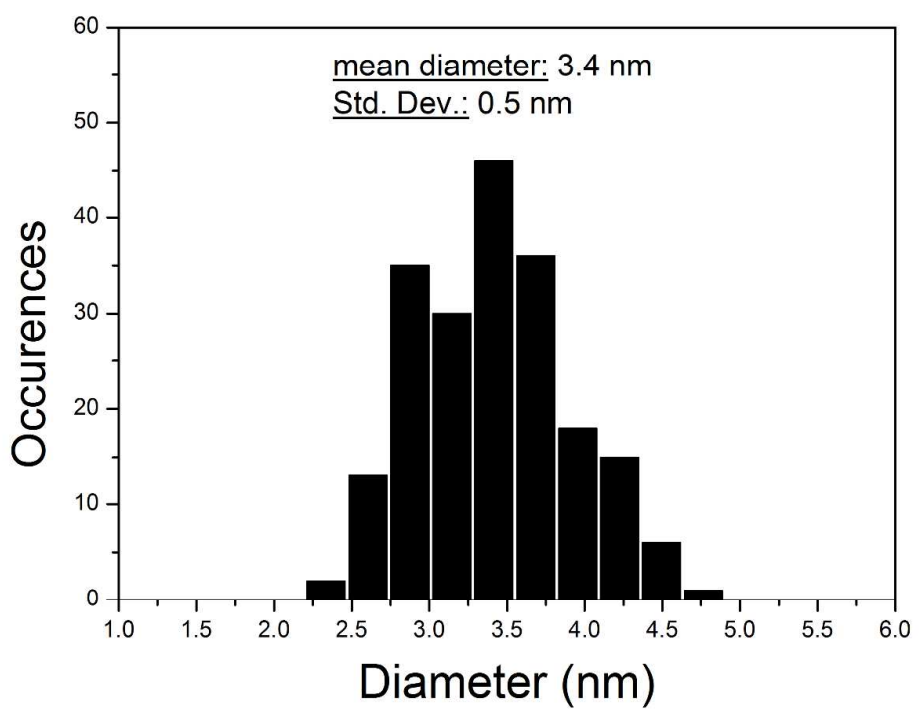

Figure S6: histogram of size distribution of InAs QDs with a first absorbance excitonic peak at $800 \mathrm{~nm}$. 


\section{S6 XRD and EDX analysis of InAs QDs.}

InAs QDs are synthesized with protocols of supporting information S1. InAs QDs and the byproduct are separated using the method of supporting information $\mathrm{S} 2.1 .5 \mathrm{~mL}$ of ethanol is added to $0.5 \mathrm{~mL}$ of the obtained InAs QDs purified solution. The mixture is precipitated using $5 \mathrm{~min}$ of centrifugation at $3700 \mathrm{rpm}$. The precipitate is suspended in $0.5 \mathrm{~mL}$ of hexane:heptane mixture (80:20 volume ratio) and drop-casted on a glass substrate. The obtained InAs QDs film is then analyzed by XRD (see figure S7 below). The XRD peaks of the analyzed InAs QDs are slightly shifted to higher angles compare to InAs zinc-blende bulk reference. An elemental analysis of the same InAs QDs sample has been performed by EDX. The InAs QDs solution has first been purified using the method of supporting information S4. The obtained solution is used to deposit the purified InAs QDs on a TEM grid by dip-coating. EDX spectrum (see figure S8) reveal that the detected amount of phosphorus is negligible ( $1 \%)$.

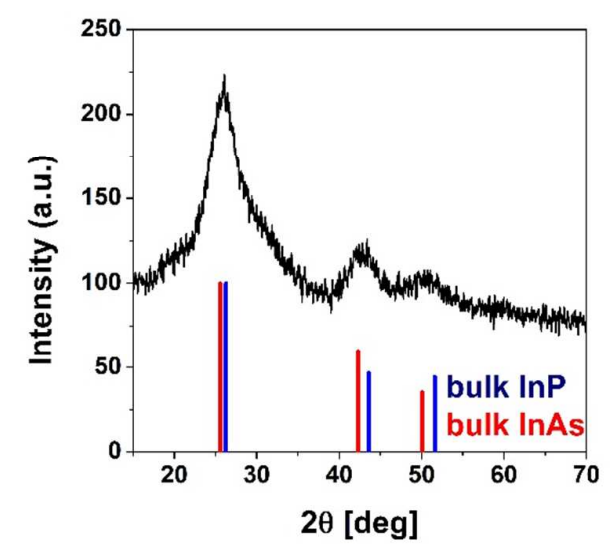

Figure S7: XRD diffractogram of InAs QDs.

\section{XRD Peak position:}

InAs QDs: $25.9^{\circ}, 42.8^{\circ}, 50.8^{\circ}$

InAs zinc-blende bulk: $25.54^{\circ}, 42.32^{\circ}, 50.08^{\circ}$

InP zinc-blende bulk: $26.28^{\circ}, 43.58^{\circ}, 51.61^{\circ}$ 


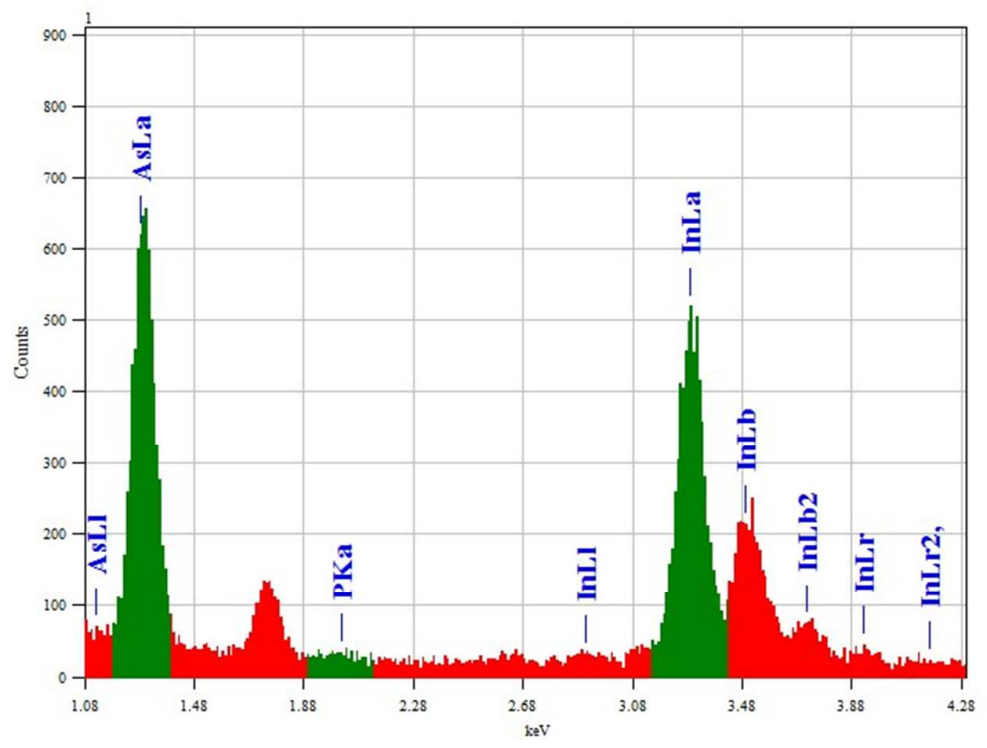

Figure S8: EDX spectrum of InAs QDs. Deduced atomic percentage (\%In: 48, \%As: 58, \%P: 1). 


\section{S7 Gas analysis of the reaction between $\mathrm{As}\left(\mathrm{NMe}_{2}\right)_{3}$ and oleylamine.}

As mentioned in the main manuscript, the transamination reaction between oleylamine and $\mathrm{As}\left(\mathrm{NMe}_{2}\right)_{3}$ should be followed by $\mathrm{Me}_{2} \mathrm{NH}$ formation (Eq.3). For qualitative confirmation of this basic gas formation, a gas trap that contain a $\mathrm{CuSO}_{4}$ aqueous solution has been mounted (Figure S9). The reaction mixture of figure S9 consists of $200 \mathrm{mg}(0.9 \mathrm{mmol})$ of indium(III) chloride and $600 \mathrm{mg}$ (4.4 mmol) of zinc(II) chloride mixed in $5.0 \mathrm{~mL}$ (15 mmol) of technical oleylamine. The reaction mixture is stirred and degassed at $120{ }^{\circ} \mathrm{C}$ for an hour and then heated to $190{ }^{\circ} \mathrm{C}$ under nitrogen. When temperature achieve $190{ }^{\circ} \mathrm{C}$, a volume of $0.17 \mathrm{~mL}$ ( $0.9 \mathrm{mmol})$ of tris(dimethylamino)arsine (In:As=1:1) is quickly injected in the mixture. This reaction results in the formation of a $\mathrm{Cu}(\mathrm{OH})_{2}$ precipitate in the gas trap solution (Figure S10). This indicates that the exhaust contains a basic gas formed during the reaction. It is consistent with a $\mathrm{Me}_{2} \mathrm{NH}$ exhaust.

Gas trap solution: $12 \mathrm{~g}$ of $\mathrm{CuSO}_{4}$ is dissolved in $250 \mathrm{~mL}$ of water.

Reaction mixture: $100 \mathrm{mg}$ of $\mathrm{InCl}_{3}, 300 \mathrm{mg}$ of $\mathrm{ZnCl}_{2}, 2.5 \mathrm{~mL}$ of oleylamine, $0.09 \mathrm{~mL}$ of $\mathrm{As}\left(\mathrm{NMe}_{2}\right)_{3}$.

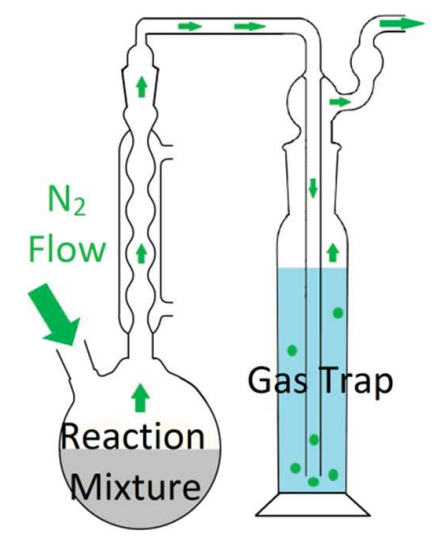

Figure S9: Scheme of the gas trap mounting. 


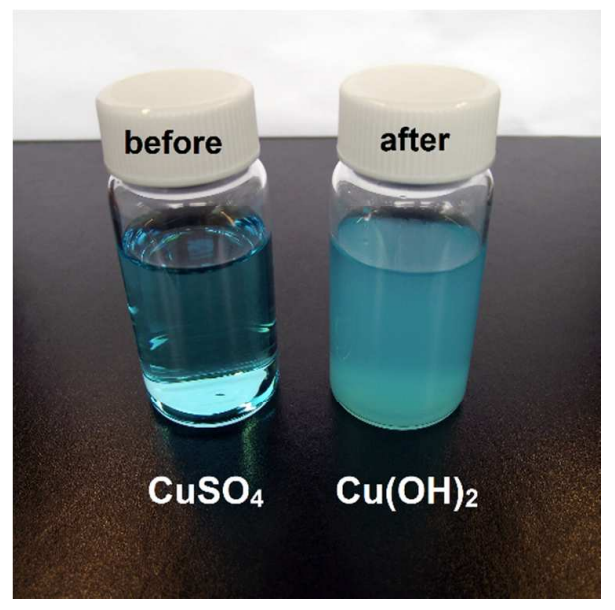

Figure S10: Gas trap solution before and after the reaction. 


\section{S8 aminoarsine:aminophosphine ratio study}

The protocol of supporting information S1 has been performed four time using different aminoarsine $\left[\mathrm{As}\left(\mathrm{NMe}_{2}\right)_{3}\right]$ to aminophosphine $\left[\mathrm{P}\left(\mathrm{NEt}_{2}\right)_{3}\right]$ ratio: 1:1, 1:2, 1:3 and 1:6. The absorbance spectra of the ended product after the purification method of supporting information S2 are presented in figure S11 below. For ratios of aminoarsine to aminophosphine of $1: 1$ and 1:2, there is no evidence of excitonic feature. For ratios of aminoarsine to aminophosphine of $1: 3$ and 1:6, an excitonic feature is observed in the absorbance spectra. EDX analysis has been performed on the QDs obtained with an aminoarsine to aminophosphine ratio of $1: 3$ and 1:6. These QDs solution have first been purified using the method of supporting information S4. These obtained solutions are used to deposit the purified QDs on a TEM grid by dip-coating. EDX spectra (see figure S12) reveal that the detected amount of phosphorus is $1 \%$ for an aminoarsine to aminophosphine ratio of $1: 3$ and $9 \%$ for an aminoarsine to aminophosphine ratio of 1:6 (see table S1).
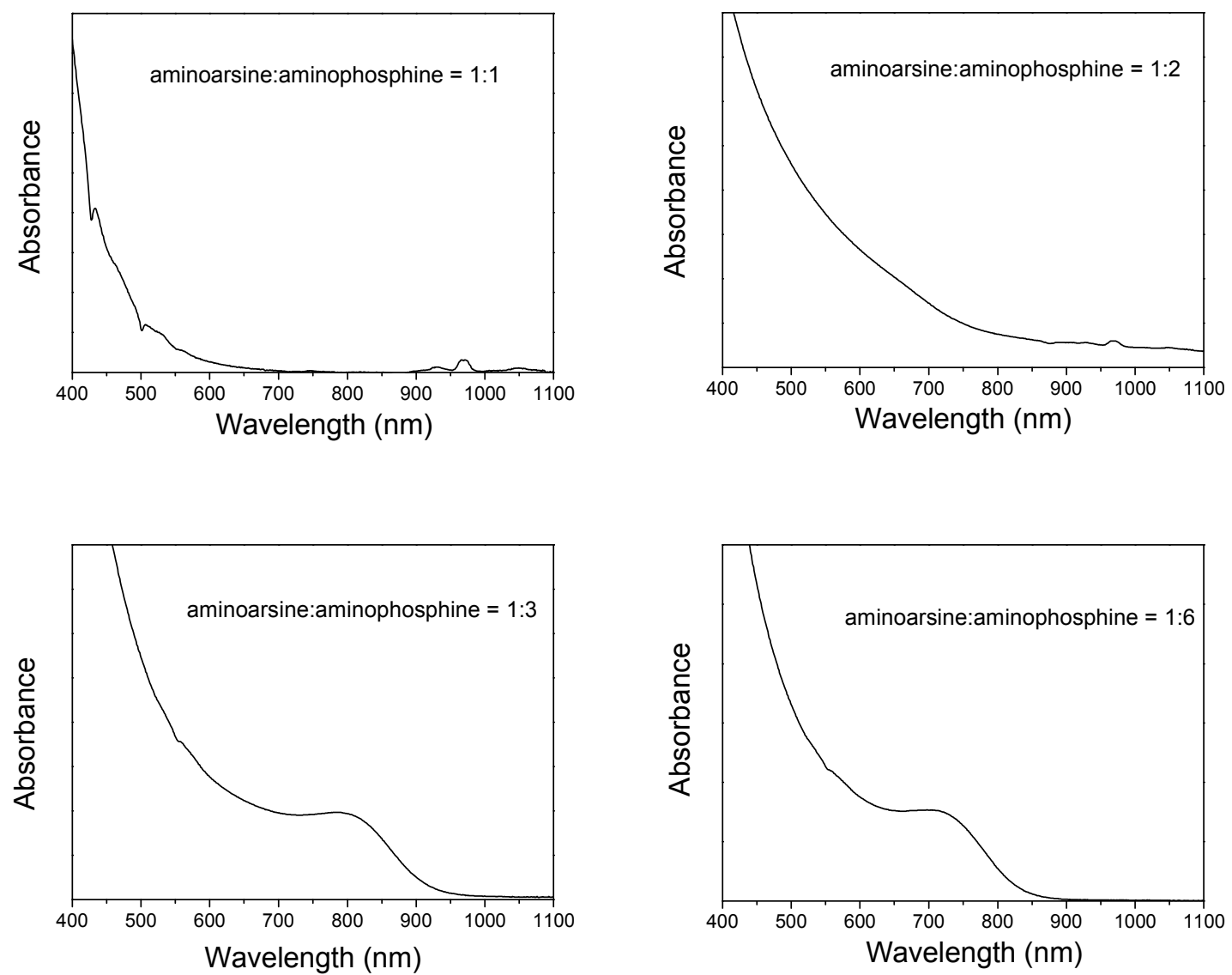

Figure S11: Absorption spectra of the obtained end products for different As:P ratio of precursors used in the synthesis. 
a.

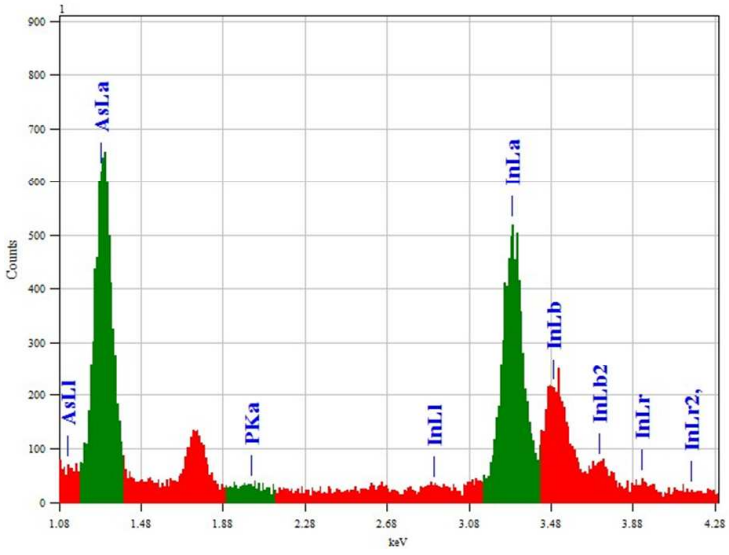

b.

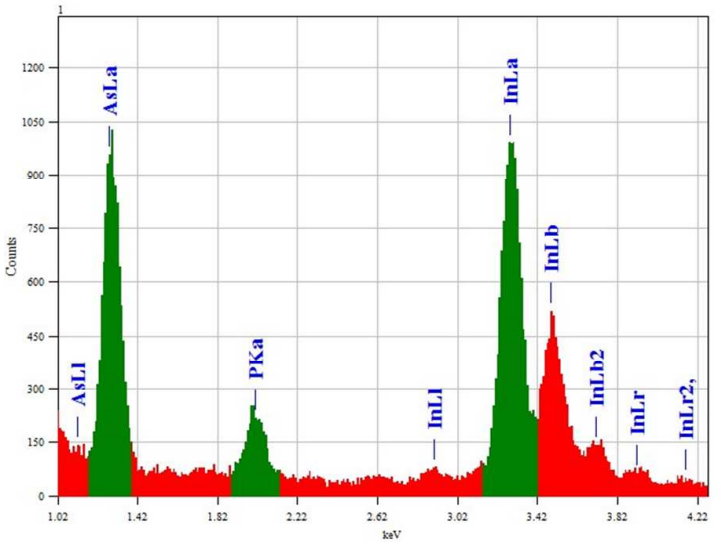

Figure S12: EDX spectra of the obtained QDs after a synthesis with a used aminoarsine:aminophosphine of a. 1:3 and b. 1:6

\begin{tabular}{|c|c|c|c|c|}
\hline As:P ratio & $1: 1$ & $1: 2$ & $1: 3$ & $1: 6$ \\
\hline $\begin{array}{c}\text { Estimated } \\
\text { chemical yield (\%) }\end{array}$ & & 40 & 60 \\
\hline $\begin{array}{c}\text { Composition } \\
\text { measured by EDX }\end{array}$ & & & $\begin{array}{c}\text { \% In: } 41 \\
\% \text { As } 58 \\
\% \text { P: } 1\end{array}$ & $\begin{array}{c}\text { \% In: } 46 \\
\% \text { As: } 45 \\
\text { \% : } 9\end{array}$ \\
\hline
\end{tabular}

Table S1: Estimated chemical yield (\% of $\mathrm{InCl}_{3}$ effectively converted in InAs) and QDs composition as a function of the As:P ratio used in the synthesis. 


\section{S9 InAs/ZnS and InAs/ZnSe QDs protocols.}

Saturated TOP-S $-0.72 \mathrm{~g}$ of sulfur powder is dissolved in $10 \mathrm{~mL}$ of TOP.

Saturated TOP-Se $-1.77 \mathrm{~g}$ of selenium powder is dissolved in $10 \mathrm{~mL}$ of TOP.

\section{S9.1 InAs/ZnS QDs}

An InAs QDs synthesis is performed at $190^{\circ} \mathrm{C}$. Instead of cooling down the reaction, at 30 minutes: $1 \mathrm{~mL}$ of stoichiometric TOP-S $(2.2 \mathrm{M})$ is slowly injected. At $60 \mathrm{~min}$ : temperature is increased from $190{ }^{\circ} \mathrm{C}$ to $200{ }^{\circ} \mathrm{C}$. At 120 minutes: slow injection of $1 \mathrm{~g}$ of $\mathrm{Zn}$ (stearate) ${ }_{2}$ in 4 $\mathrm{mL}$ of octadecene. Temperature is increased from $200{ }^{\circ} \mathrm{C}$ to $220^{\circ} \mathrm{C}$. At 150 minutes: injection of $0.7 \mathrm{~mL}$ of stoichiometric TOP-S (2.2 M). Temperature is increased from $220^{\circ} \mathrm{C}$ to $240{ }^{\circ} \mathrm{C}$. At 180 minutes: slow injection of $0.5 \mathrm{~g}$ of $\mathrm{Zn}$ (stearate) ${ }_{2}$ in $2 \mathrm{~mL}$ of octadecene. Temperature increased from $240^{\circ} \mathrm{C}$ to $260^{\circ} \mathrm{C}$. At 210 minutes: end of reaction. At the end of the reaction, the temperature is cooled down. InAs/ZnS nanocrystals are then precipitated in ethanol and suspended in toluene.

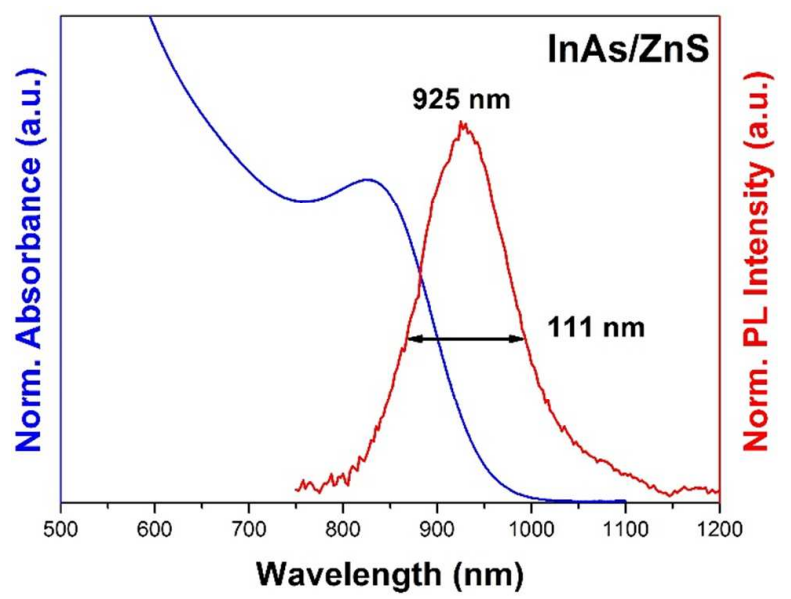

Figure S13. Absorbance and emission spectra of InAs/ZnS QDs.

\section{S9.2 InAs/ZnSe QDs}

An InAs QDs synthesis is performed at $190^{\circ} \mathrm{C}$. Instead of cooling down the reaction at 30 minutes: slow injection of $1 \mathrm{~mL}$ of stoichiometric TOP-Se (2.2 M). At $60 \mathrm{~min}$ : temperature is increased from $190{ }^{\circ} \mathrm{C}$ to $200{ }^{\circ} \mathrm{C}$. At 120 minutes: slow injection of $1 \mathrm{~g}$ of $\mathrm{Zn}$ (stearate) ${ }_{2}$ in 4 $\mathrm{mL}$ of octadecene. Temperature is increased from $200{ }^{\circ} \mathrm{C}$ to $220^{\circ} \mathrm{C}$. At 150 minutes: injection of $0.7 \mathrm{~mL}$ of stoichiometric TOP-Se (2.2 M). Temperature is increased from $220^{\circ} \mathrm{C}$ to $240{ }^{\circ} \mathrm{C}$. At 180 minutes: end of reaction. At the end of the reaction, the temperature is cooled down. InAs/ZnSe nanocrystals are then precipitated in ethanol and suspended in toluene. 


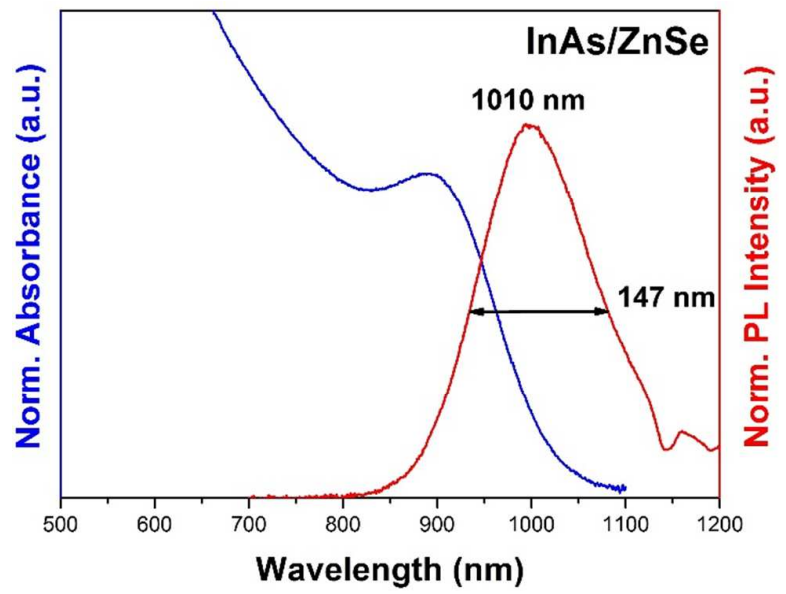

Figure S14. Absorbance and emission spectra of InAs/ZnS QDs. 


\section{S10 TEM pictures of InAs/ZnS and InAs/ZnSe QDs}

InAs/ZnS(e) QDs are synthesized with protocols of supporting information S9. InAs/ZnS(e) QDs and sediment are separated by decantation (cf. supporting information S2). $0.6 \mathrm{~mL}$ of octylamine and $1.2 \mathrm{~mL}$ of ethanol is added to $0.2 \mathrm{~mL}$ of InAs/ZnS(e) QDs ( $5 \%$ of the total amount of one reaction). The mixture is precipitated using $5 \mathrm{~min}$ of centrifugation at 3700 $\mathrm{rpm}$. The precipitate is suspended in $0.2 \mathrm{~mL}$ of toluene and $1 \mathrm{~mL}$ of octylamine and $0.8 \mathrm{~mL}$ of ethanol are added to the obtained solution. The resulting mixture is then centrifuged for 5 $\min$ at $3700 \mathrm{rpm}$ and the obtained precipitate is suspended in $0.2 \mathrm{~mL}$ of toluene. The obtained solution is used to deposit the purified InAs/ZnS(e) QDs on a TEM grid by dipcoating.

a.

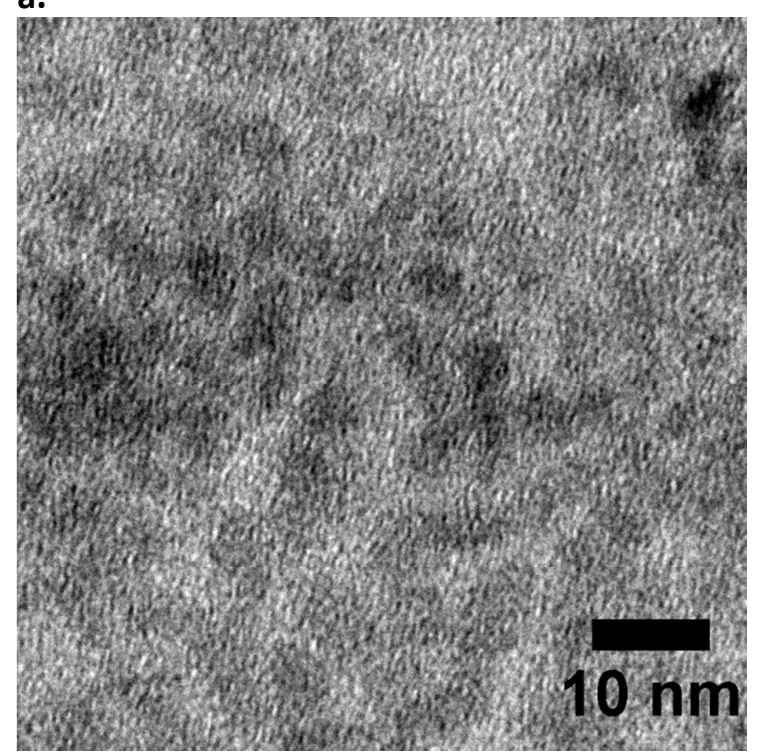

b.

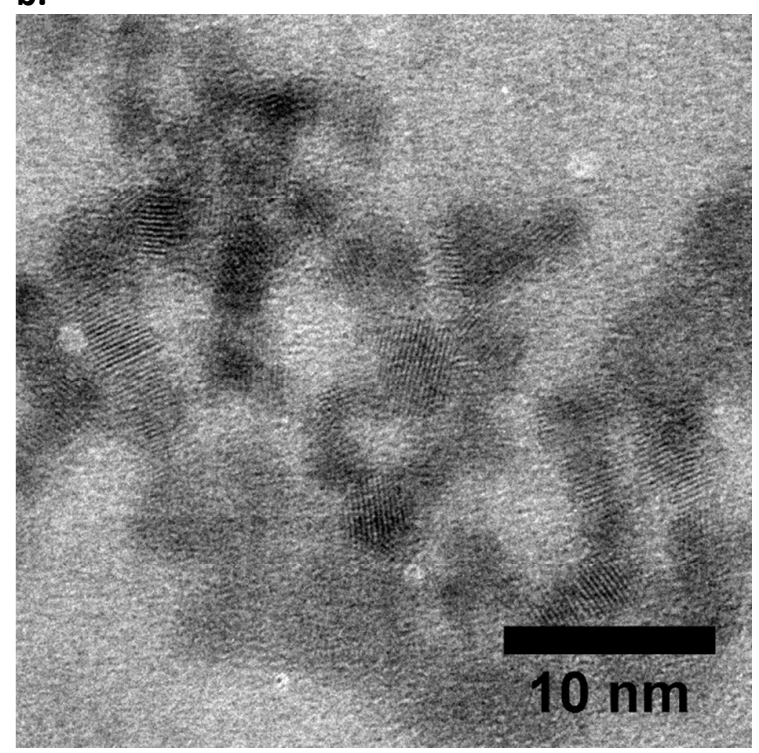

Figure S15. TEM pictures of a. InAs/ZnS and b. InAs/ZnSe core/shell QDs. 


\section{S11 XRD diffractograms of InAs/ZnS and InAs/ZnSe QDs}

InAs/ZnS(e) QDs are synthesized with protocols of supporting information S9. InAs/ZnS(e) QDs and sediment are separated by decantation (cf. supporting information S2). $1.5 \mathrm{~mL}$ of ethanol is added to $0.5 \mathrm{~mL}$ of the obtained $\operatorname{InAs} / \mathrm{ZnS}(\mathrm{e})$ QDs purified solution. The mixture is precipitated using $5 \mathrm{~min}$ of centrifugation at $3700 \mathrm{rpm}$. The precipitate is suspended in 0.5 $\mathrm{mL}$ of hexane:heptane mixture (80:20 volume ratio) and drop-casted on a glass substrate. The obtained InAs QDs film is then analyzed by XRD (see figure S16 below).
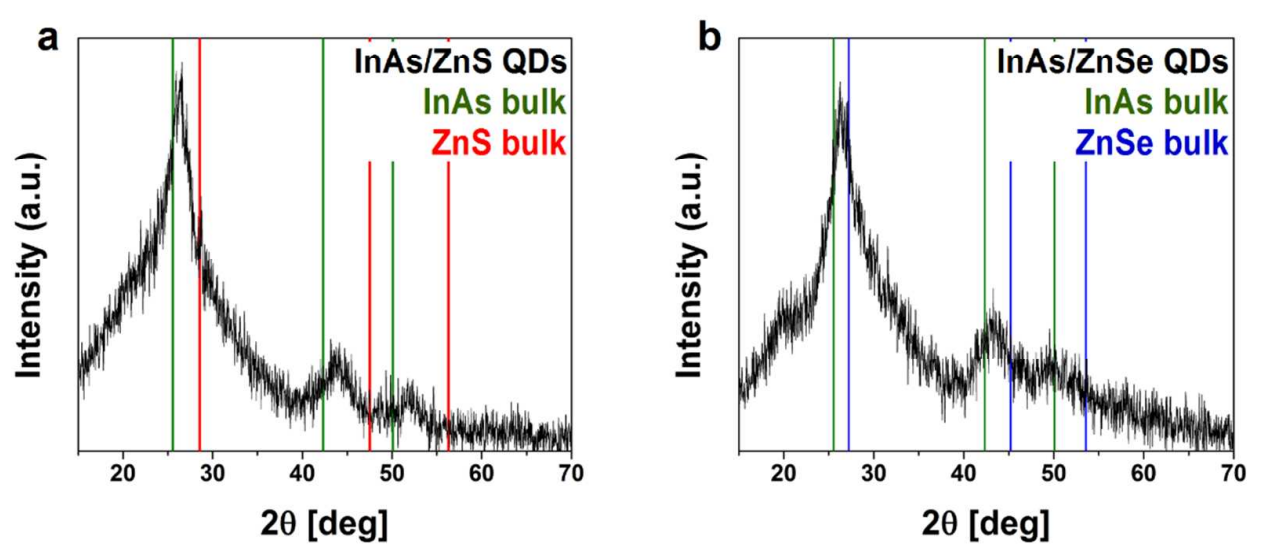

Figure S16. XRD diffractograms of a. InAs/ZnS and b. InAs/ZnSe core/shell QDs.

\section{Peaks position:}

XRD InAs/ZnSe QDs: $27.3^{\circ}, 45.3^{\circ}, 53.6^{\circ}$

InAs/ZnS QDs: $27.3^{\circ}, 45.9^{\circ}$

InAs zinc-blende bulk: $25.54^{\circ}, 42.32^{\circ}, 50.08^{\circ}$

ZnS zinc-blende bulk: $28.56^{\circ}, 47.51^{\circ}, 56.29^{\circ}$

ZnSe zinc-blende bulk: $27.22^{\circ}, 45.19^{\circ}, 53.57^{\circ}$ 


\section{References}

1. J. Leatherdale, C. A.; Woo, W. K.; Mikulec, F. V; Bawendi, M. G. J. Phys. Chem. B 2002, 106, 7619.

2. Karel Čapek, R.; Moreels, I.; Lambert, K.; De Muynck, D.; Zhao, Q.; Van Tomme, A.; Vanhaecke, F.; Hens, Z. J. Phys. Chem. C 2010, 114, 6371.

3. Aspnes, D. E.; Studna, A. A. Phys. Rev. B 1983, 27, 985.

4. Debenham, M.; Dew, G. D. J. Phys. E. 2000, 14, 544. 